\title{
Explore on the Relationship between Pre- Figurative Culture and University Innovation and Entrepreneurship Education Model
}

\author{
Liu Xueping \\ Engineering Training Center \\ Shenyang Aerospace University \\ Shenyang, China
}

\author{
Zhang Senyue \\ School of Economy and Management \\ Shenyang Aerospace University \\ Shenyang, China
}

\begin{abstract}
With the improvement of China's sanitation vocational education, universities ask higher requirement on teaching quality. Traditional university education takes old teaching models as the core, however, when students and parents ask higher requirement on education, sky rocketing defects are exposed which cannot be adapted to the requirement of modern education. In order to comply with development needs, lots of universities integrate innovative pattern of pre-figurative culture with traditional teaching to carry out university education with a different way. Based on practice, make up for each other's deficiencies and reciprocal combination, the teaching quality is improved. Besides, in order to response to the call of the Ministry of national education, the combination of innovative mode of pre-figurative culture and traditional teaching should be applied in practice, aiming to acquire better teaching results, and provide references for universities to explore a new path.
\end{abstract}

Keywords-Pre-figurative culture; Innovation model; Traditional teaching; University education; Teaching experience

\section{INTRODUCTION}

China's development requires the power of innovation, while universities are main forces to innovate thinking, technique and knowledge and it is of great significance to carry out reform and innovation in university education and to cultivate innovative quality shall be deemed as the targets and pursuit of every university. Higher education should realize the transition from knowledge inculcation to innovative model of pre-figurative culture with innovative spirit and innovative ability as the core[1]. So, universities have to change ideas and combine teaching practice to strengthen students ' ability of applying theory, enhance practice and innovation ability in order to cultivate qualified practical talents with innovative ability through solid work.

\section{LIMITATIONS OF TRADITIONAL TEACHING MODEL}

After a period of transition, traditional teaching model are still dominant and its teaching mode takes teacher explanation as the core. In traditional classroom teaching, teachers play the main role and a common phenomenon is that teachers talking while students listening which is a typical cramming method of teaching. Its merit is that it can spread large amount of teaching information with theoretical knowledge systematicness[2]. However, its demerits are obvious: students are passive and lack enthusiasm because of this simple teaching model let alone creativity and independence. Therefore, it is urgent to cultivate students' subjective initiative.

\section{ADVANTAGES OF APPLYING INNOVATIVE TEACHING MODEL OF PRE-FIGURATIVE CULTURE}

The idea of pre-figurative culture is firstly put forward in Culture and Commitment written by American famous cultural anthropologist Mead, which is a special term for human beings to transmit culture and carry out intergenerational communication. Mead points out that the arrival of pre-figurative culture shall ignite the transition of modern higher education model[3].

The innovative model of pre-figurative culture is different from traditional teaching model which takes problems as the basis and was firstly mentioned in 1960s while professor Barrows introduces this teaching model in western university education. Comparing to traditional teaching mode, it has different focus which pays more attention to students' subjective initiative and helps students participate in learning management and form the habit of coming up with problems and solve problems on their own. Through such teaching practice, students are able to carry out exploration via different means under the guidance of teachers, including referring to books, watching online materials etc which can improve students' enthusiasm and meanwhile improve the education quality. Besides, students shall be equipped with more independent thinking model and bold as well as innovative spirit of learning.

Cooperative teaching combining innovative teaching model of pre-figurative culture and traditional teaching

Each teaching mode has their own weaknesses and strengths, yet traditional teaching model has inevitably created obstacles for students to carry out independent learning. However, it also has obvious advantages for example, teachers can transfer knowledge to students via systematic approaches which greatly reduce the time for students to search materials and is conducive to improve learning efficiency. The adoption of innovative model of pre-figurative culture has more advantages which yet has defects. For example, it shall be beneficial to cultivate subjective initiative and innovation, however it can not independently and quickly satisfy the learning requirement of students because of the restriction of real consideration and different conditions. Besides, this teaching model asks higher requirement on students and they must maintain 
good learning attitude and be strict with oneself. Moreover, it should be supported by technologies with diverse requirements. In developing countries like China, purely adopting the innovative model is not suitable which has to be adjusted so as to be in accordance with China's basic national conditions and in line with education requirements[4]. Therefore, in the context of the special conditions of China, the combination of this innovative model and traditional model is proper so as to complement each other and improve education quality.

Take mathematics as an example. As an abstract discipline, students shall encounter a lot of problems. High school math teaching advocates life style to create an embodiment from giving lecture to set questions so as to make students be close to life[5]. In addition, the close combination of math and practice shall make the teaching process more vivid. Interest is the best teacher, and only when teachers grasp their interests can they able to improve the teaching efficiency.

Cold and hard statistics do not have a soul which cannot attract all the students while the mathematical phenomena occur around them may attract their attention because the surrounding environment is closely related to themselves. Besides, students should be engaged in math and combine reality with formulas in the book to feel its value [6]. According to investigations, some students do not understand this subject because of its abstraction which cannot be imagined with the brain. So, the adoption of real cases to give scientific explanation can create deeper impression. For example: while studying elementary geometry, familiar brands can be used to demonstrate features and differences; while learning probability, teachers can take advantage of lucky draw to explain its concept. To conclude, such vivid and interesting approaches can help students better remember the knowledge points.

Street billboards, tall buildings, unsteady swing are all related to math and students have already had mathematical experiences in real life while teachers should be responsible to connect them with academic definition. Especially in high school math, most of the formulas come from real life and the appearance demonstrated can help students create a good habit for them to ponder. Life experience can be used to help students explore math knowledge, so in whole teaching, the responsibility of teachers is not only convey knowledge but also help students put it into real life and make students become the core of teaching. As a teenage youth, they have accumulated a lot of hidden knowledge, they know how to sum 1 to 100 with a simpler way and which kind of shape is more stable and whey they cannot see the end of the world. For example, before using a mathematical apparatus, students can be asked to elaborate their understanding and use methods and then introduce relevant math knowledge which can guarantee organic connection of memory as well as textbook knowledge while students shall suddenly see the light and have deeper interests to learn. Maybe students learn knowledge from textbooks in order to deal with exams which cannot be the original intention. Math, as a special discipline, it is closely related to practice, and its aim is to apply into practice so as to bring along with more convenience. Besides, teachers can organize students to participate in math lecture and practices etc so as to help them improve their operation ability. Meanwhile, students shall be asked to deepen the relationship between math and social life to expand knowledge and promote interest development in terms of scientific technology. In teaching program, teachers can properly add social practice adopt different activities and carry out social survey or visit etc. Of course, math cannot be separated from science, which can help students know what math can do and how to do. However, it should not be simple demonstration while students can carry out scientific manufacturing and research mathematics etc[8].

\section{CONCRETE PRACTICE OF COOPERATIVE TEACHING IN UNIVERSITIES}

\section{A. Practice objects}

Select students of two classes in universities as samples, among which $\mathrm{A}$ acts as the experiment class and adopts cooperative teaching model combining innovative model of pre-figurative culture and traditional teaching while B acts as the control class and adopts traditional teaching model. To conclude, there are not significant difference in age, gender and academic achievement without statistical significance $(\mathrm{P}>0.05)$ which are comparable.

\section{B. Practice methods}

Control class continues to use the traditional teaching mode mainly by professors giving lectures. Experiment class adopts the cooperative teaching model combining innovative model of pre-figurative culture and traditional teaching while general University theory knowledge is told by professor in collective class and the innovative model is used to carry out practice and concrete implementation steps show as follows: first, teachers prepare the innovative model of pre-figurative culture based on the teaching content and specific situation of students, which should be evaluated; second, teachers randomly divide students into groups and each group has 7 students with one acting as the leader; third, teacher send out the research topic and each group carry out independent learning with discussion, they can refer to materials and give a solution and report the result on schedule. After reporting the result, they can comment or raise questions; fourth, after the completion of reporting, teachers should comment on each group and point out demerits as well as merits to draw a conclusion and help them summarize key points and difficult points.

\section{Assessment method}

Two methods can be adopted to evaluate the cooperative teaching model combining innovative model of pre-figurative culture and traditional teaching: first, questionnaire; second, final examinations and assessment. The questionnaire is taken by secret ways while final examinations and assessment mainly evaluate their comprehensive analysis and application ability which shall be corrected based on same answer.

\section{Results}

100 questionnaires issued are all recycled and the recycling efficiency is $100 \%$. According to data statistics, $91 \%$ students think that cooperative teaching model combining innovative model of pre-figurative culture and traditional teaching can help to improve learning initiative 
and $82 \%$ them hold the idea that it can enhance memory of theoretical knowledge while over $90 \%$ of them believe it is also able to enhance teamwork spirit and competitive consciousness and $95 \%$ think that it can inspire interest. In final exam and assessments, the record of experiment class is obviously better than the control class, indicating that this cooperative teaching model is conducive to improve education quality.

\section{CONCLUSION}

With the improvement of China's sanitation vocational education, universities ask higher requirement on teaching quality. Traditional university education takes old teaching models as the core, however, when students and parents ask higher requirement on education, sky rocketing defects are exposed which cannot be adapted to the requirement of modern education. The adoption of cooperative teaching model combining innovative model of pre-figurative culture and traditional teaching can create satisfying results which change the passive situation and improves learning efficiency. To conclude, its main advantage is that it can not only help students learn systematic professional knowledge but also increase their learning enthusiasm and foster students ' creative quality. The organic combination shall better comply with modern education needs comparing to the traditional one, which will inevitably become a breakthrough and help to realize new change of university education model.

\section{REFERENCES}

[1] Huang Cenhan, Liu Yanping, Zhu Meizhen etc. Explore on the innovation education and talent cultivation model of university education[J]. Journal of Guangxi colleges and universities, 2004, 7 (4) : 110-112.

[2] Guo Xiaopeng, Cui Qi, Ma Chao. Discussion on the application of innovative teaching model of pre-figurative culture in practical education[J]. Xinjiang Journal of Traditional Chinese Medicine, 2005,23 (2) : :55-56.

[3] Zhang Qingyun, Zhu Hui, Han Xiang. The application of organic combination of innovative teaching model of pre-figurative culture and traditional teaching in medical chemistry [ J ] . China's higher education,2010 (12) : 97-99.

[4] Wang Ping. Adopt life-oriented Math teaching to guide high school mathematics teaching[J]. Mathematics, physics and chemistry learning, 2010.14 (11) : 38-40.

[5] Han Hengfu. Cognition and practice of life-oriented Math teaching in high school [J].MiddleSchool, 2013.9 (14) : 86.

[6] Liu Yongtao. Brief discussion on the implementation principle and strategy of innovation education in high school $[\mathrm{J}]$. Mathematics, physics and chemistry learning, 2012.3 (12) : 34-36.

[7] Guan Zhao. Reflections and practice of innovation education in universities [J]. Mathematics, physics and chemistry learning, 2013.13 (3) : 23.

[8] Han Guangjun. Cognition and practice of innovation education in universities [J]. 2013.10（5）: 67-68.

[9] University innovation and entrepreneurship education course[M], Hou WenhuaScience, Press2012,30-37. 